Dublin Institute of Technology

ARROW@DIT

2008-01-01

\title{
High Performance ZnO Varistors Prepared From Nanocrystalline Precursors for Miniaturised Electronic Devices
}

Suresh Pillai

Dublin Institute of Technology, suresh.pillai@dit.ie

Declan E. McCormack

declan.mccormack@dit.ie

John Kelly

Raghavendra Ramesh

Follow this and additional works at: http://arrow.dit.ie/ahfrcart

Part of the Chemical Engineering Commons, Materials Science and Engineering Commons, and the Systems and Communications Commons

\section{Recommended Citation}

Pillai, S. C., Kelly, J.M. McCormack, D. E. Raghavendra, R., "High Performance ZnO Varistors Prepared from Nanocrystalline Precursors for Miniaturised Electronic Devices", Journal of Materials Chemistry, 18, 2008, 3926-3932

This Article is brought to you for free and open access by the Antenna \& High Frequency Research Centre at ARROW@DIT. It has been accepted for inclusion in Articles by an authorized administrator of ARROW@DIT. For more information, please contact yvonne.desmond@dit.ie, arrow.admin@dit.ie.

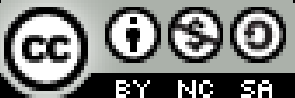




\title{
High performance $\mathrm{ZnO}$ varistors prepared from nanocrystalline precursors for miniaturised electronic devices $\dagger$
}

\author{
Suresh C. Pillai, ${ }^{a}$ John M. Kelly, ${ }^{* b}$ Declan E. McCormack ${ }^{* c}$ and Raghavendra Ramesh ${ }^{d}$ \\ Received 20th March 2008, Accepted 30th May 2008 \\ First published as an Advance Article on the web 8th July 2008 \\ DOI: 10.1039/b804793f
}

\begin{abstract}
An industrially viable solution-based processing route using minimal amounts of solvent has been used to prepare bulk quantity nanopowders (average particle size $15 \pm 3 \mathrm{~nm}$ ) for the fabrication of $\mathrm{ZnO}$ varistors. The xerogels, calcined powders and sintered materials were fully characterised. The preparation of varistors from nanopowders has been optimised by studying the effect of temperature on grain growth, densification and breakdown voltage. The varistors are prepared by sintering at $1050{ }^{\circ} \mathrm{C}$ for 2 hours, a temperature that is significantly lower than that used in the current industrial process. Highly dense varistor discs prepared from the sintered material produce devices, with a breakdown voltage $85 \%$ higher than that of commercial varistors, making them suitable for use in miniaturised electronic circuitry. Improved performance of these materials has been attributed to the small grain size and better dispersion of additives on $\mathrm{ZnO}$ grains.
\end{abstract}

\section{Introduction}

Varistors are ceramic-based semiconductors that are used in many areas of electronics and communication technology. ${ }^{1-7}$ The function of a varistor is to sense and limit over-voltage surges and to function continuously without loss of performance. ${ }^{1} \mathrm{ZnO}$ varistors were initially developed using a solid-state mixing of $\mathrm{ZnO}$ and metal oxide additives by Matsuoka ${ }^{7}$ in 1970, and such solid-state processing is still the preferred method in the industry. ${ }^{1,5}$ This is achieved by the mixing of 0.5 to $3 \mu \mathrm{m} \mathrm{ZnO}$ particles with dopant oxides such as $\mathrm{Bi}_{2} \mathrm{O}_{3}, \mathrm{Sb}_{2} \mathrm{O}_{3}, \mathrm{CoO}, \mathrm{MnO}$, $\mathrm{NiO}$ and $\mathrm{Cr}_{2} \mathrm{O}_{3}$. The mixed powder is then pressed and sintered at high temperatures $\left(1200-1300{ }^{\circ} \mathrm{C}\right)$. This simple method of processing powder has led to its utilisation on an industrial scale. The low cost associated with the use of comparatively inexpensive oxide powders is also commercially attractive. The main disadvantage of this route, however, is the difficulty in obtaining compositional homogeneity, which is especially important for the preparation of the miniaturised devices required for modern electronic equipment. ${ }^{1,5}$

Preparative methods, crystallite size and additive homogeneity are the critical parameters to produce a better varistor material. ${ }^{8-19}$ In particular inhomogeneous microstructures can cause

${ }^{a}$ Center for Research in Engineering Surface Technology (CREST), FOCAS Institute, Dublin Institute of Technology, Camden Row, Dublin 8,Ireland.E-mail: Suresh.pillai@dit.ie

${ }^{b}$ School of Chemistry, University of Dublin, Trinity College, Dublin 2, Ireland.E-mail: jmkelly@tcd.ie; Fax: +353-1-6712826; Tel: +353-1-8961947

'School of Chemical and Pharmaceutical Sciences, Dublin Institute of Technology, Kevin Street, Dublin 8, Ireland. E-mail: declan. mccormack@dit.ie; Fax: +353-1-4024989; Tel: +353-1-4024778

${ }^{d}$ Littelfuse Ireland Ltd., Ecco Road, Dundalk, Ireland. E-mail: rraghave@, littelfuse@dit.ie

$\uparrow$ Electronic supplementary information (ESI) available: Fig. S1-S7 and Tables S1-S3. See DOI: 10.1039/b804793f degradation of varistors during electrical operation. ${ }^{1}$ Electrical and electronic characteristics can be altered by varying the microstructure at the grain boundaries. ${ }^{3,5,8}$ Thus, careful control of the microstructure is required to produce the perfect varistor. Nanoparticles yield a narrow grain size distribution and can be sintered at a lower temperature compared to coarse grained ceramics. ${ }^{3,5,6,8}$ The temperature required for sintering also depends on the particle size and on the distribution of dopants among the individual grains. Nanometre-sized material contains large grain boundary volumes and should therefore yield more varistor active grain boundaries per unit volume, allowing one to develop a better device with smaller dimensions. However, controlling grain growth during sintering is a challenge for $\mathrm{ZnO}$ nanomaterials research. For example Ya et al. ${ }^{11}$ prepared $20 \mathrm{~nm}$ $\mathrm{ZnO}$ particles using zinc nitrate, citric acid and ethylene glycol. However, further dopant addition and sintering (densification $=$ 98\%) produced $2 \mu \mathrm{m}$ grains. By such wet chemical methods, homogeneity of the dopant ions among the $\mathrm{ZnO}$ grains can be achieved at the molecular level, something that is difficult to achieve by any conventional ceramic route.

Several attempts using chemical methods have been reported for the production of varistor materials..$^{3,5,6,8-19} \mathrm{We}$ have recently found that nano- $\mathrm{ZnO}$ synthesised from zinc acetate dihydrate and oxalic acid dihydrate either by a solution route ${ }^{18}$ or by a solid-state pyrolysis route ${ }^{19}$ can be used to produce varistors with an improved breakdown voltage. Furthermore, core-shelltype varistor materials fabricated by coating metal salts on previously calcined $\mathrm{ZnO}$ nanoparticles were found to give superior electrical properties, which were attributed to better homogeneity of additive ions among the $\mathrm{ZnO}$ grains. ${ }^{5}$ However, the densification obtained on sintering at $1050{ }^{\circ} \mathrm{C}$ for many of these materials was inadequate for optimum industrial fabrication. ${ }^{5,6,18,19}(>98 \%$ densification is required for industrial handling and integration of these materials into electronic devices). Thus, there is a need for a new bulk processing route 
that could produce a fully dense varistor at a lower temperature with superior electrical properties. Here, we report a novel mixed precursor method (MPR) involving soluble metal salts, oxalic acid, diethanolamine and ethyleneglycol in ethanol solution. Unlike many of the above mentioned laboratory methods, the route proposed here is easily scaled-up for the production of nanomaterials for the fabrication of high performance varistors. Furthermore, these materials gives a higher breakdown voltage compared to the other reported methods (and significantly greater breakdown voltage compared to the commercial samples) and show high densification at a temperature $150{ }^{\circ} \mathrm{C}$ lower than the commercial standard (the current commercial sintering temperature is $1200{ }^{\circ} \mathrm{C}$ ).

\section{Experimental}

\section{Reagents}

The following reagents were used without further purification. Zinc acetate dihydrate (Riedel-de Haen, $99.5 \%$ ), bismuth(III) nitrate pentahydrate (Aldrich, 98\%), antimony(III) acetate (Aldrich, 99\%), cobalt(III) acetate tetrahydrate (Aldrich, 98\%), manganese(II) acetate tetrahydrate (Aldrich, 99\%), nickel(II) acetate tetrahydrate (Aldrich, 99\%), chromium(III) nitrate nonahydrate (Aldrich, 99\%) and aluminium nitrate nonahydrate (Aldrich, 99\%). Minor amounts of two industrial proprietary dopants were used as received.

\section{Large-scale synthesis of varistor materials by sol-gel mixed precursor route.}

Zinc acetate dihydrate $(274.50 \mathrm{~g}, 1.25 \mathrm{~mol})$, cobalt acetate tetrahydrate $(3.60 \mathrm{~g}, 14 \mathrm{mmol})$, manganese acetate tetrahydrate $(3.20 \mathrm{~g}, 13 \mathrm{mmol})$ nickel acetate tetrahydrate $(1.85 \mathrm{~g}, 7.4 \mathrm{mmol})$ and aluminium nitrate nonahydrate $(0.090 \mathrm{~g}, 0.24 \mathrm{mmol})$ were mixed with ethanol $(2.5 \mathrm{~L})$ and diethanolamine $(60.5 \mathrm{~mL}$, $625 \mathrm{mmol}$ ) and dissolved by boiling in a $5 \mathrm{~L}$ flask. A pink solution was obtained after 20 minutes. Simultaneously, the second solution containing bismuth nitrate pentahydrate $(6.30 \mathrm{~g}, 13.9$ $\mathrm{mmol})$, antimony acetate $(9.80 \mathrm{~g}, 32 \mathrm{mmol})$ chromium nitrate nonahydrate $(5.25 \mathrm{~g}, 13 \mathrm{mmol})$ in ethylene glycol $(250 \mathrm{~mL}$, $4.55 \mathrm{mmol}$ ) was prepared in a $500 \mathrm{~mL}$ conical flask by warming $\left(60{ }^{\circ} \mathrm{C}\right)$ and stirring. A homogeneous green solution was obtained after 20 minutes. The first solution was allowed to cool for 15 minutes and then transferred to a $5 \mathrm{~L}$ beaker. The second solution was added to the first and stirred for 15 minutes with an overhead stirrer. To this solution oxalic acid (315 g, $2.50 \mathrm{mmol})$ dissolved in ethanol (1L) was added with vigorous stirring. A thick semi-gel was obtained. Stirring was continued for another 15 minutes. The gel was poured into an evaporating dish and put it into an oven set at $80{ }^{\circ} \mathrm{C}$ for 12 hours. The dried powder was calcined at $500{ }^{\circ} \mathrm{C} .2 \mathrm{~g}$ of the above material was plastified with $0.5 \mathrm{~mL}$ each of $10 \%$ aqueous solution of poly(vinyl alcohol) and poly(ethylene glycol) and $0.015 \mathrm{~g}$ of gum arabic. This was further dried in an oven for 5 minutes and pelletised into $7 \mathrm{~mm} \times 0.7 \mathrm{~mm}$ discs for further sintering and electrical studies. The pellets were sintered at $1050{ }^{\circ} \mathrm{C}$ and held at this temperature for 2 hours in a chamber furnace under air atmosphere.

\section{Instrumentation}

Morphology and microstructure of the materials prepared were probed with transmission electron microscopy (TEM) and scanning electron microscopy (SEM). TEM was performed using a Hitachi 7000 TEM or Philips CM 20 HRTEM (high resolution transmission electron microscope). 400 mesh copper grids coated with formvar were used to prepare the samples. SEM studies were carried out by FESEM (Hitachi S-4300), which was operated at $5.0 \mathrm{kV}$ or $20 \mathrm{kV}$. Samples for analysis were mounted on aluminium stubs and coated with graphite. The BET surface area analysis of the $500{ }^{\circ} \mathrm{C}$ calcined powder was carried out using a Gemini 2370 instrument operating at liquid nitrogen temperature after degassing the samples for 2 hours at $200{ }^{\circ} \mathrm{C}$. Calcined and sintered powders were examined by X-ray diffraction (XRD). XRD samples were prepared by making a thin film of the powder with acetone on a glass plate, and the measurement was performed with a Siemens D500 or Philips PW1540 X-ray diffractometer. The particle sizes were calculated by using the Scherrer equation. ${ }^{5,18,20}$ Thermal decomposition characteristics of the samples were studied by differential scanning calorimetric (DSC) measurements and thermo-gravimetric analysis (TGA). DSC was performed with a Rheometric Scientific DSC QC. A small amount of sample (less than $3 \mathrm{mg}$ ) was heated from room temperature to $500^{\circ} \mathrm{C}$ at a constant heating rate of $10^{\circ} \mathrm{C}$ per min under a nitrogen atmosphere. TGA was carried out using a Thorn Scientific TG-750 instrument operated at a constant heat flow of $1{ }^{\circ} \mathrm{C}$ per min. Electrical characteristics of the sintered varistor materials were measured by using a Keithley Instrument (Model 2410). The breakdown voltage $\left(V_{\mathrm{c}}\right)$ was measured as the voltage at a current density of $1 \mathrm{~mA}$. Density measurements of the pre-sintered and sintered samples were performed using Archimedes principle. The determinations were carried out in water using an Ohaus densitometer 470007-010.

\section{Results and discussion}

\section{Synthetic procedures}

The MPR nanopowders were prepared by the following procedure. An ethanolic solution of zinc acetate, cobalt acetate, manganese acetate, nickel acetate and diethanolamine and an ethylene glycol solution containing antimony acetate, bismuth nitrate and chromium nitrate were mixed. To this was added an ethanolic solution of oxalic acid, which produced a semi-gel. Subsequent drying at $80{ }^{\circ} \mathrm{C}$ produced a xerogel. This material was then calcined at $500{ }^{\circ} \mathrm{C}$ to produce a free-flowing nanopowder (full details are given in the Experimental section). The synthetic method employs low volumes of solvents as the diethanolamine enhances the solubility of metal salts (e.g. $110 \mathrm{~g}$ $\mathrm{L}^{-1}$ ). This facilitates the preparation of $\mathrm{ZnO}$ nanoparticular materials in far more concentrated solutions than previously reported by other authors. ${ }^{21,22}$ Diethanolamine has also been found to be an effective stabilising agent for titania-based sol-gel materials. ${ }^{23}$ Thus, an industrially and environmentally friendly method is proposed using a much reduced volume of solvents to prepare the varistor materials in bulk quantities. It should also be noted that the solvent (ethanol) used in the process may readily be recycled. 


\section{Characterisation of the precursor xerogel}

The xerogel $\left(80{ }^{\circ} \mathrm{C}\right.$ dried) before calcining at $500{ }^{\circ} \mathrm{C}$ was pale violet in colour with a porous nature. FESEM images (Fig. 1) shows rod/sheet like morphologies of $1-1.5 \mu \mathrm{m}$ in length and 0.3 to $0.5 \mu \mathrm{m}$ in thickness. In a previous study, rod-like morphologies with $0.6 \mu \mathrm{m}$ in length and $50 \mathrm{~nm}$ widths were obtained for the nanowire precursor xerogel. ${ }^{18}$ In that case the zinc acetate to diethanolamine mole ratio was $1: 0.1$, but here we use a mole ratio of $1: 0.5$. The increase in dimension of the rods is apparently due to the increase in the amount of diethanolamine. ${ }^{18}$

The thermo-gravimetric analysis (TGA) curve of the xerogel is shown in Fig. 2. A total weight loss of $72 \%$ is obtained. Three stages of weight loss are observed at $110-200{ }^{\circ} \mathrm{C}, 320-380{ }^{\circ} \mathrm{C}$, and $450-480^{\circ} \mathrm{C}$. The first stage of the weight loss $\left(110-200^{\circ} \mathrm{C}\right)$ is regarded as the removal of acetate groups ${ }^{5,18}$ and the second stage of weight loss $\left(320-380{ }^{\circ} \mathrm{C}\right)$ can be explained as the removal of chelated diethanolamine, ${ }^{18}$ and $\left(450-480{ }^{\circ} \mathrm{C}\right)$ is explained as the formation of $\mathrm{ZnO}$ from the decomposition of the precursors. ${ }^{5,18} \mathrm{X}$-Ray diffraction results showed that the $\mathrm{ZnO}$ formation occurred after $250{ }^{\circ} \mathrm{C} .{ }^{24}$ The transitions observed with TGA are reflected in those determined by DSC (Fig. S1, see ESI $\dagger$ ). The endotherm at $175{ }^{\circ} \mathrm{C}$ is attributed to the removal of acetate groups. The peak at $274{ }^{\circ} \mathrm{C}$ and $365^{\circ} \mathrm{C}$ may be assigned to the elimination of free- and chelated diethanolamine, respectively. ${ }^{23,25}$ Finally, a transition observed at $454{ }^{\circ} \mathrm{C}$ is suggested to be due to the formation of $\mathrm{ZnO} .^{5,18,26}$ A DSC scan of the same material (in the second cycle) did not show any peaks indicating the formation of a thermally stable material as expected. These

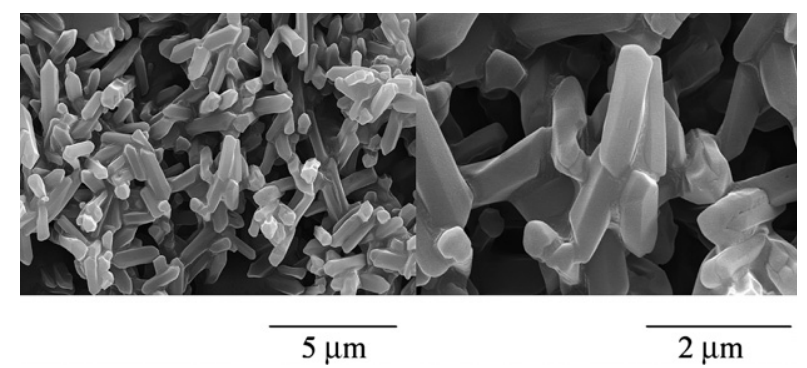

Fig. 1 FESEM images of the $80{ }^{\circ} \mathrm{C}$ dried nano-varistor precursor prepared by sol-gel mixed precursor route.

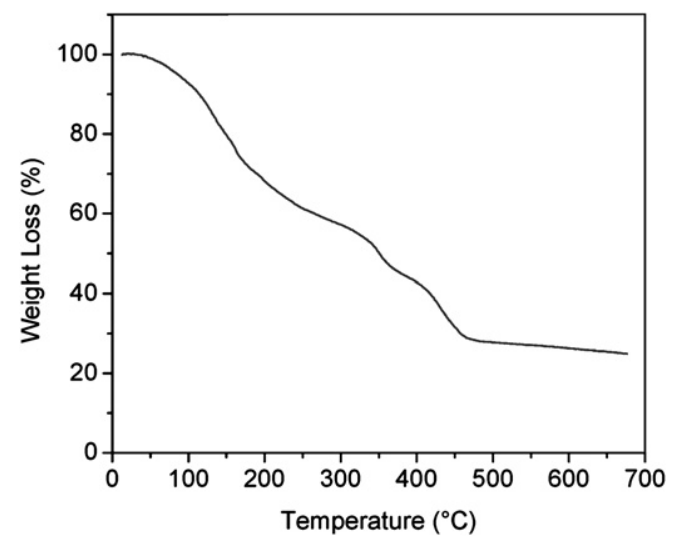

Fig. 2 TGA pattern of xerogel, dried at $80^{\circ} \mathrm{C}$, prepared by sol-gel mixed precursor route. results indicate that $500{ }^{\circ} \mathrm{C}$ is the suitable temperature to calcine the xerogel to produce $\mathrm{ZnO}$ powders.

\section{Characterisation of MPR nanopowders}

The xerogel dried at $80^{\circ} \mathrm{C}$ was calcined to $500{ }^{\circ} \mathrm{C}$ for 2 hours and the powder obtained was analysed by X-ray powder diffraction (XRD) which showed the presence of only $\mathrm{ZnO}$ (Fig. S2, see ESI $\dagger$ ). This is either due to the fact that the dopant concentration is below the detection limit or that they do not form crystalline phases.

The observed broadening of the X-ray bands allowed an estimate of the average particle size as $15 \pm 3 \mathrm{~nm}$ using the Scherrer equation. ${ }^{5,20}$ This particle size is found to be somewhat smaller than that of the pure $\mathrm{ZnO}(19 \pm 4 \mathrm{~nm})$ prepared analogously in the absence of dopants. ${ }^{18}$ This observed decrease in the resultant particle size is possibly due to the effect of $\mathrm{Sb}_{2} \mathrm{O}_{3}$, which is added as a grain growth inhibitor in varistor ceramics. ${ }^{1}$

The presence of crystalline phases of $\mathrm{ZnO}$ was further confirmed by the selected area electron diffraction pattern (SAED pattern (Fig. S3, see ESI $\dagger$ ). Crystalline planes and $d$ values calculated were in agreement with the XRD pattern (Table $\mathrm{S} 1$, see ESI $\dagger$ ). The presence of additives ( $\mathrm{Sb}, \mathrm{Bi}, \mathrm{Cr}$ and $\mathrm{Ni}$ ) in the microstructure could be observed from EDX analysis of the nanopowder (Fig. S4, see ESI $\dagger$ ).

The calcined powders were subjected to BET surface area analysis and a value of $45 \mathrm{~m}^{2} \mathrm{~g}^{-1}$ was obtained. This is a very high surface area compared to the commercial varistor sample (supplied by Littelfuse Ireland Ltd), which has a surface area of $2.8 \mathrm{~m}^{2} \mathrm{~g}^{-1}$. These MPR nanopowders contain an appreciable amount of agglomerates of stick-like morphologies, as evidenced from the FESEM images (Fig. 3a and 3b). The length of these

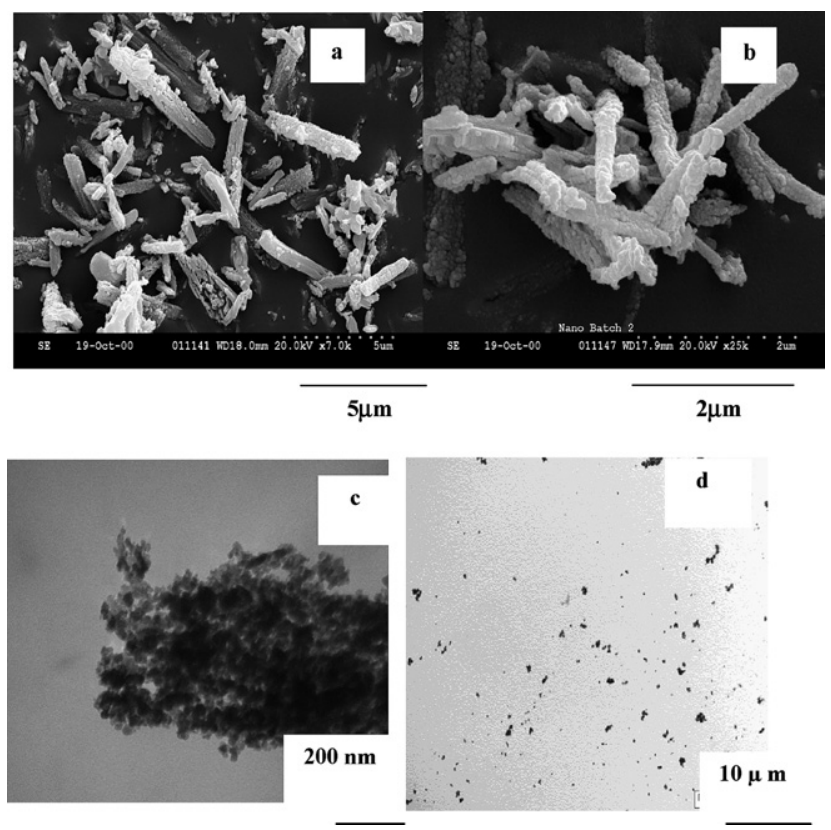

Fig. 3 FESEM and TEM images of the $500{ }^{\circ} \mathrm{C}$ nano-varistor powder prepared by 'sol-gel mixed precursor' route; FESEM (before milling) magnified at a) $7 \mathrm{k}$ and b) $25 \mathrm{k}$ TEM images; c) agglomerates magnified at $50 \mathrm{k}$; d) after milling, magnified at $3.5 \mathrm{k}$. 
stick-like structures varies from $2-4 \mu \mathrm{m}$ with a width of $0.3-$ $0.5 \mu \mathrm{m}$. At higher magnification (e.g. $50 \mathrm{k}$ ) it could be seen that these sticks are made up of smaller particles (Fig. 3c). Ultrasonication for up to 40 minutes did not have any deagglomerating effect.

As strong agglomerates may lead to larger grains after sintering, ${ }^{27}$ ball milling was used to fragment these and hence lead to nanopowder de-agglomeration. ${ }^{27}$ The ball milling was carried out at three different conditions for 30 minutes: i) aqueous milling; ii) aqueous milling in poly-acrylic acid medium; and iii) dry milling. TEM results demonstrated that dry milling for 30 minutes significantly helps to decrease strong agglomerates (Fig. 3d). Milling in water or in polyacrylic acid solution was much less effective.

\section{Sintering and grain growth in discs made from MPR nanopowder}

It is recognised that the basic building block of the $\mathrm{ZnO}$ varistor are the $\mathrm{ZnO}$ grains formed as result of sintering. ${ }^{1,19}$ During sintering the additives become organised in such a way in the microstructure that the near grain boundary region becomes highly resistive $\left(r_{\mathrm{gb}} \sim 10^{12} \Omega \mathrm{cm}\right)$ and the grain interior becomes highly conducting. ${ }^{1}$

The final grain size of a typical commercial varistor after sintering is of the order of $8-12 \mu \mathrm{m}$ and the corresponding breakdown voltage is around $2-3 \mathrm{kV} \mathrm{cm}^{-1}$, which is equivalent to a voltage drop of 1.6 volts per intergranular barrier, ${ }^{17}$ as the breakdown voltage of the sintered body is proportional to the number of grain boundaries. Nanocrystalline material contains large grain boundary volumes and more varistor active grain boundaries per unit volume can be produced in order to develop a better device with smaller dimensions. Sintering experiments have been performed at various temperatures from $700{ }^{\circ} \mathrm{C}$ to $1050{ }^{\circ} \mathrm{C}$ for 2 hours in a chamber furnace. Samples were heated at a rate of $1.5^{\circ} \mathrm{C}$ per min up to $300{ }^{\circ} \mathrm{C}$, held for one hour at that temperature (to facilitate binder burn off). They were then ramped at $3{ }^{\circ} \mathrm{C}$ per min to the final temperature and held at this value for 2 hours. Varistor discs prepared from nano-size precursors were calcined and then dry ball milled $(30 \mathrm{~min})$. The colour of the pre-sintered pellets was dark green and changed to light green after sintering at $700{ }^{\circ} \mathrm{C}$ and $800{ }^{\circ} \mathrm{C}$.

The colour of the pellets changed to black at $900^{\circ} \mathrm{C}$ and higher temperatures. Densities were measured and plotted against temperatures (Fig. 4a). It is seen from the figures that the sintered density is considerably increased at $900{ }^{\circ} \mathrm{C}$ and at $1050{ }^{\circ} \mathrm{C}$ close to $100 \%$ sintered density is obtained (compared to the theoretical density of fully sintered $\mathrm{ZnO}$ ).

The dimensions of the pellets were also considerably decreased at $900{ }^{\circ} \mathrm{C}$ compared to lower temperature sintered samples and linear and volume shrinkages were calculated. There is no shrinkage observed up to $800{ }^{\circ} \mathrm{C}$, however at $900{ }^{\circ} \mathrm{C}$ a linear shrinkage of $23 \%$ and a volume shrinkage of $52 \%$ were observed compared to the pre-sintered sample.

The sintering behaviour was further confirmed by dilatometric studies (Fig. 4c). The dilatometer curve obtained at a rate of $5^{\circ} \mathrm{C}$ per min revealed that the onset of sintering occurred in the range $875-925{ }^{\circ} \mathrm{C}$ and is finished in the range $1025-1050{ }^{\circ} \mathrm{C}$. The dilatometer curve obtained for the commercial sample at a rate of $5{ }^{\circ} \mathrm{C}$ per min revealed that the onset of sintering occurred in the
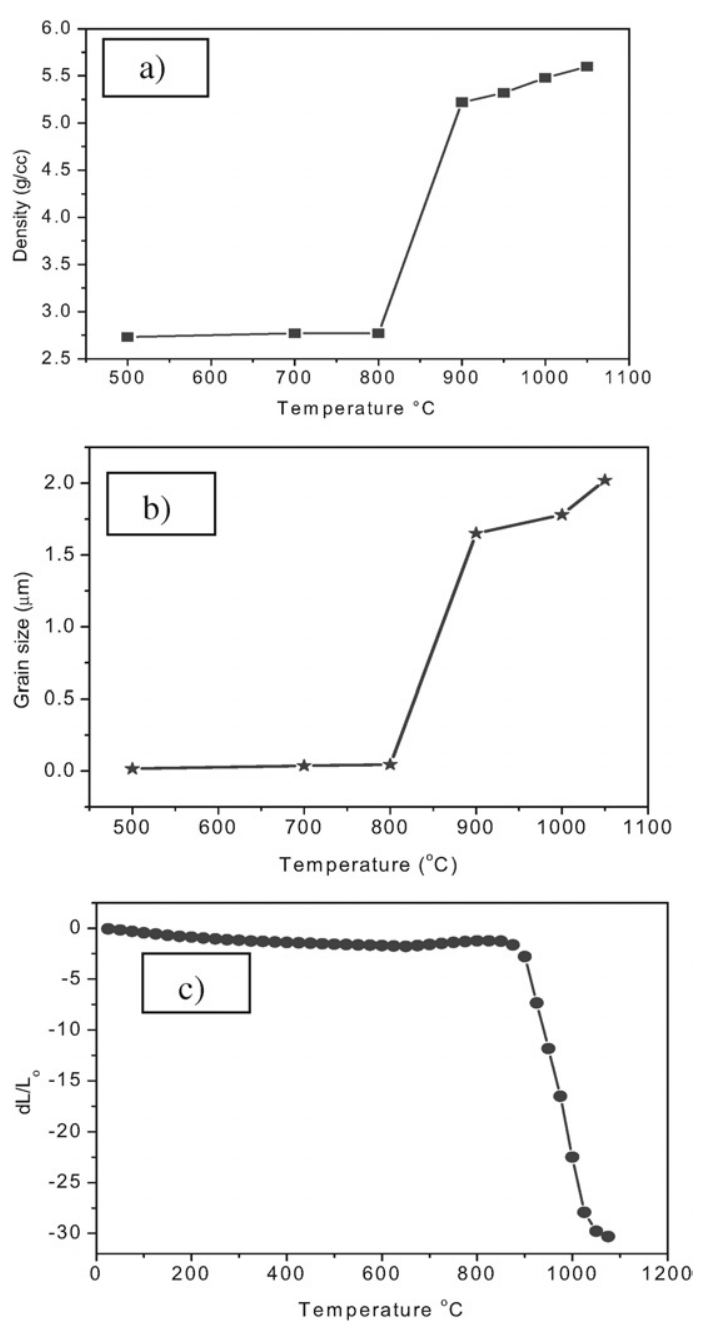

Fig. 4 a) Change in density with temperature, b) grain size $v s$. temperature, and c) dilatometer curve of varistor MPR nanopowder.

range $900-925^{\circ} \mathrm{C}$ and was not finished even at $1050{ }^{\circ} \mathrm{C}$. Thus a much better sinterability at lower temperature is obtained for nano-varistor precursor samples.

Grain growth is often associated with the final stages of sintering and usually both processes occur simultaneously. ${ }^{6,11,28-30}$ FESEM studies were performed to verify whether this was the case here (Fig. 5). A plot of grain size vs. temperature is given in Fig. 4b. At $700{ }^{\circ} \mathrm{C}$ the particle size was found to be 36 $\pm 5 \mathrm{~nm}$, and at $800{ }^{\circ} \mathrm{C}$ it was estimated as $45 \pm 5 \mathrm{~nm}$. A grain size of $1.60 \pm 0.05 \mu \mathrm{m}$ was obtained at a sintering temperature of $900{ }^{\circ} \mathrm{C}$ (Fig. 5c), and the grains had further grown to $2.02 \pm$ $0.5 \mu \mathrm{m}$ after heating at $1050{ }^{\circ} \mathrm{C}$ for $2 \mathrm{~h}$ (Fig. 5d). This demonstrates that sintering is accompanied by grain growth especially between $800{ }^{\circ} \mathrm{C}$ and $900{ }^{\circ} \mathrm{C}$. However, the final grain size is still significantly smaller than that in sintered commercial materials.

\section{Characterisation of the sintered samples}

Metal oxide varistors contain $\mathrm{ZnO}$ grains as the major component $(92-95 \%)$ with several other metal oxides as additives. Each of the additives influence one or more of the properties, such as 

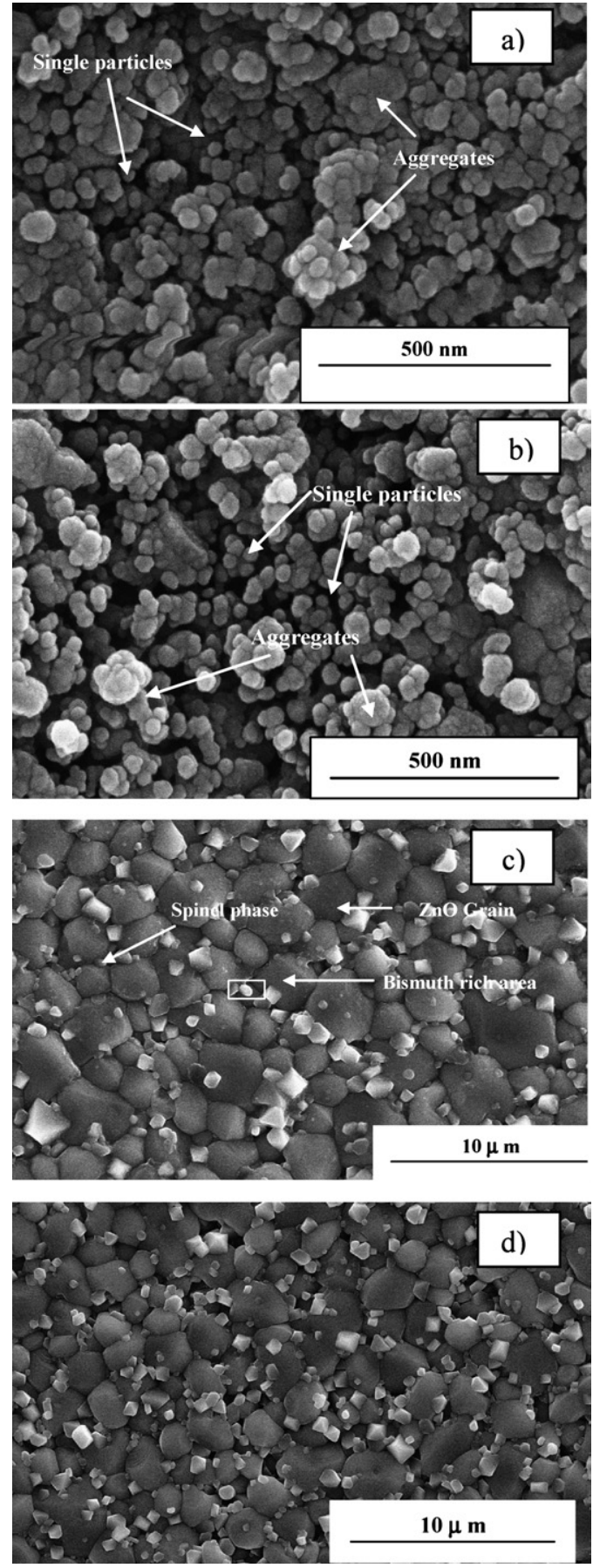

Fig. 5 FESEM of varistors prepared by sol-gel mixed precursor route sintered at a) $700{ }^{\circ} \mathrm{C}$, b) $800{ }^{\circ} \mathrm{C}$, c) $900{ }^{\circ} \mathrm{C}$, and d) $1050{ }^{\circ} \mathrm{C}$.

the electrical characteristics (breakdown voltage, non-linearity and leakage current), grain growth and sintering temperature. ${ }^{1,31}$ $\mathrm{Bi}_{2} \mathrm{O}_{3}$ is the most essential component for producing non-ohmic behaviour whilst addition of $\mathrm{CoO}$ and $\mathrm{MnO}$ enhances non-linear properties. ${ }^{1,31,32} \mathrm{~A}$ very low concentration of $\mathrm{Al}_{2} \mathrm{O}_{3}$ increases the $\mathrm{ZnO}$ grain conductivity and $\mathrm{Sb}_{2} \mathrm{O}_{3}$ controls the $\mathrm{ZnO}$ grain growth. ${ }^{1,931}$ During sintering, different phases are formed and the microstructure of a $\mathrm{ZnO}$ varistor comprises conductive $\mathrm{ZnO}$ grains surrounded by electrically insulating grain boundary regions. The $\mathrm{ZnO}-\mathrm{Bi}_{2} \mathrm{O}_{3}-\mathrm{Sb}_{2} \mathrm{O}_{3}$ system forms a pyrochlore phase, $\mathrm{Zn}_{2} \mathrm{Bi}_{3} \mathrm{Sb}_{3} \mathrm{O}_{14}$, above $650{ }^{\circ} \mathrm{C} .{ }^{33}$ Together with $\mathrm{ZnO}$, the pyrochlore $\left(\mathrm{Zn}_{2} \mathrm{Bi}_{3} \mathrm{Sb}_{3} \mathrm{O}_{14}\right)$ further reacts to form a spinel $\left(\mathrm{Zn}_{7} \mathrm{Sb}_{2} \mathrm{O}_{12}\right)$ according to:

$$
2 \mathrm{Zn}_{2} \mathrm{Bi}_{3} \mathrm{Sb}_{3} \mathrm{O}_{14}+17 \mathrm{ZnO} \rightarrow 3 \mathrm{Zn}_{7} \mathrm{Sb}_{2} \mathrm{O}_{12}+3 \mathrm{Bi}_{2} \mathrm{O}_{3}
$$

Thus, the following three major components should be detected in a typical varistor microstructure. ${ }^{1,33,34}$ a) $\mathrm{ZnO}$ grains; b) $\mathrm{Zn}_{7} \mathrm{Sb}_{2} \mathrm{O}_{12}$, spinel crystal structure; c) bismuth-rich phases. Varistors, prepared from nano-size precursors after milling, and sintered at $1050{ }^{\circ} \mathrm{C}$ for $2 \mathrm{~h}$ were studied in detail by XRD and microstructural analysis (see Fig. S6, ESI $\dagger$ ). Zinc oxide, spinel and bismuth-rich phases could be identified from the XRD pattern ${ }^{1,6}$, (see Fig. S6, ESI $\dagger$ ). Similar patterns (see Fig. S7, ESI $\dagger$ ) were identified for commercial samples sintered at $1050^{\circ} \mathrm{C}$ for 2 h. The FESEM micrographs of the nano-samples sintered at $1050{ }^{\circ} \mathrm{C}$ for $2 \mathrm{~h}$ are shown in Fig. 5d. Microstructures obtained were similar to earlier reports ${ }^{9,5}$ and different phases were identified with EDX analysis. In order to identify different phases, EDX analysis was carried out for the nano-samples sintered at $1050{ }^{\circ} \mathrm{C}$ for $2 \mathrm{~h}$. As expected, three phases can be identified by EDX: a) $\mathrm{ZnO}$ phase (Fig. 6a); b) spinel, $\mathrm{Zn}_{7} \mathrm{Sb}_{2} \mathrm{O}_{12}$, phases found at the triple points and also on the grains (Fig. 6b); and c) bismuth-rich phase found in intergranular grains and at triple points (Fig. 6c).

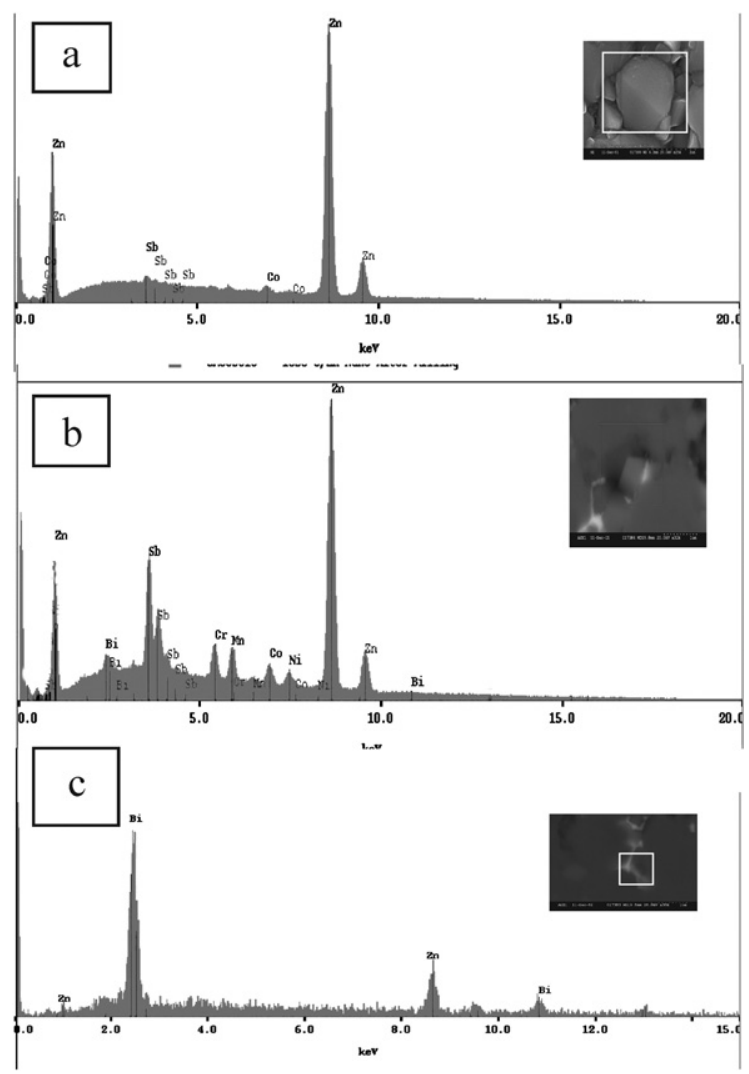

Fig. 6 EDX image of a) $\mathrm{ZnO}$ grains, b) spinel $\left(\mathrm{Zn}_{7} \mathrm{Sb}_{2} \mathrm{O}_{12}\right)$ phase, and c) EDX pattern of the bismuth-rich phase (white areas in the microstructure). 

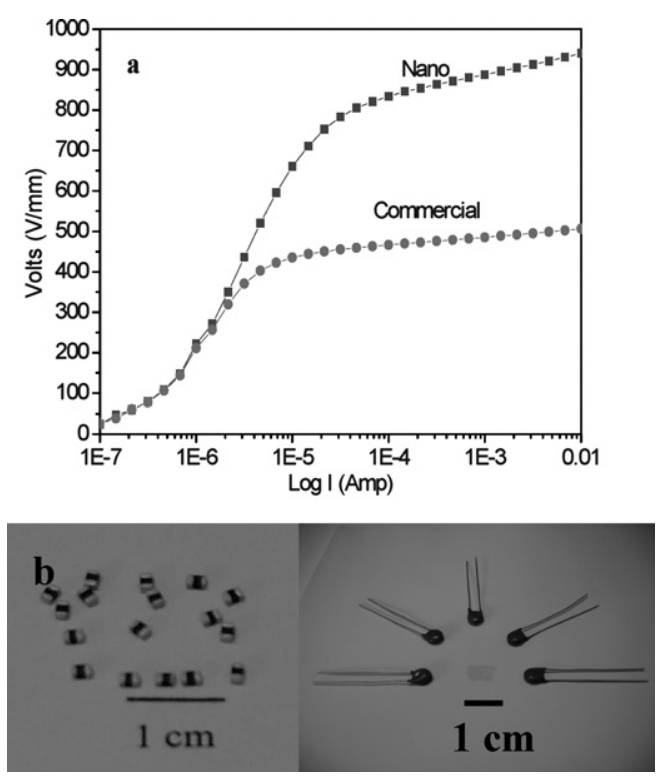

Fig. 7 Varistor samples prepared by sintering at $1050^{\circ} \mathrm{C}$ : a) $I-V$ curve, b) varistors fabricated using MPR method.

\section{Electrical characterisation of varistor discs made using the MPR nanopowder}

To assess the MPR powder as a varistor precursor, discs were prepared, sintered and electrodised. The current-voltage characteristics of these devices compared with commercial samples are given in Fig. 7. A considerably higher breakdown voltage $\left(V_{\mathrm{c}}\right)$ is obtained for samples prepared from MPR nano-samples $\left(941 \pm 30 \mathrm{~V} \mathrm{~mm}^{-1}\right)$ compared to commercial samples $(507 \pm 30 \mathrm{~V}$ $\left.\mathrm{mm}^{-1}\right)$. The $V_{\mathrm{c}}$ obtained for materials prepared by this route is also higher than the previously reported nano-array material $\left(786 \pm 30 \mathrm{~V} \mathrm{~mm}^{-1}\right)^{18}$ nano-ZnO by sol-gel route $(683 \pm 30 \mathrm{~V}$ $\left.\mathrm{mm}^{-1}\right),{ }^{5}$ core-shell-type material $\left(850 \pm 30 \mathrm{~V} \mathrm{~mm}^{-1}\right),{ }^{5}$ and nano $\mathrm{ZnO}$ by solid-state pyrolysis route $\left(656 \pm 30 \mathrm{~V} \mathrm{~mm}^{-1}\right){ }^{19}$ The MPR nano-varistor showed an $\alpha$ value of $33 \pm 3\left[V_{2}=735 \mathrm{~V}\right.$; $\left.V_{1}=640 \mathrm{~V}\right]$, whereas the commercial varistors showed an $\alpha$ value of $28 \pm 3\left[V_{2}=390 \mathrm{~V} ; V_{1}=330 \mathrm{~V}\right]$ (Table 1$)$.

These properties may also be compared to varistor devices prepared from precursor powder formed by solid-state mixing of the metallic precursors and oxalic acid. Subsequent calcinations and sintering of these materials under identical conditions were carried out. However, electrical studies showed that these materials did not possess any varistor properties (see Fig. S5, ESI $\dagger$ ). This can be attributed to the inhomogeneity of the

Table 1 Densification and electrical properties of samples sintered at $1050{ }^{\circ} \mathrm{C}$ for $2 \mathrm{~h}$

\begin{tabular}{|c|c|c|c|}
\hline Varistor sample & $\begin{array}{l}\text { Sintered } \\
\text { density }\left(\mathrm{g} \mathrm{cm}^{-3}\right)\end{array}$ & $\begin{array}{l}\% \\
\text { Densification }\end{array}$ & $\begin{array}{l}V_{\mathrm{c}} \pm \\
\left(\mathrm{V} \mathrm{mm}^{-1}\right)\end{array}$ \\
\hline MPR & 5.58 & 99.60 & 859 \\
\hline Commercial & 5.40 & 96.44 & 507 \\
\hline Core-shell ${ }^{4}$ & 5.45 & 97.21 & 850 \\
\hline Nano-array ${ }^{18}$ & 5.38 & 96.00 & 786 \\
\hline Nano $\mathrm{ZnO}$ (sol-gel) ${ }^{18}$ & 5.17 & 92.30 & 683 \\
\hline Nano $\mathrm{ZnO}$ (solid state) ${ }^{19}$ & 5.11 & 91.41 & 656 \\
\hline
\end{tabular}

dopants distributed among the $\mathrm{ZnO}$ grains. This reaction confirms the needs for homogeneous solution processing.

The improved breakdown voltage of the varistors prepared from the MPR nano-size precursors compared to the commercial sample can be explained on the basis of the smaller grain size of the MPR nanomaterial. $99.6 \%$ densification was obtained for nano samples sintered at $1050{ }^{\circ} \mathrm{C}$ for 2 hours. This is also much better than previously reported materials (Table 1 ).

In order to understand the effect of grain size of nano- $\mathrm{ZnO}$ on breakdown voltage, sintering experiments at 950 and $1000{ }^{\circ} \mathrm{C}$ for $2 \mathrm{~h}$ have also been carried out. A considerably higher breakdown voltages of $1450 \mathrm{~V} \mathrm{~mm}$ md $^{-1}$ and $\mathrm{V} \mathrm{mm}^{-1}$ were obtained for samples prepared from nano samples compared to the commercial samples (Table S3 and S4, ESI $\dagger$ ). However, the density measurements show that the sintering was not complete and further higher temperature sintering was required to achieve better density $(>98 \%)$ for industrial handling. These results further attribute that breakdown voltage is directly proportional to the number of active varistor grain boundaries (which is directly related to grain size, see Fig. 4b) per unit area.

\section{Conclusions}

A novel mixed precursor method for the production of $\mathrm{ZnO}$ based varistor powder has been successfully and reproducibly developed. As produced powders are composed of agglomerates of ultra fine $(\sim 15 \mathrm{~nm})$ doped $\mathrm{ZnO}$ particles that can be broken up by dry ball milling for 30 minutes. Varistors were fabricated from these nano-materials by sintering at various temperatures ranging from 700 to $1050{ }^{\circ} \mathrm{C}$. Full densification, high breakdown voltage $\left(941 \pm 30 \mathrm{~V} \mathrm{~mm}^{-1}\right.$; which is $85 \%$ higher than the commercial varistor at $1050{ }^{\circ} \mathrm{C}$ ) and a reasonably good nonlinear coefficient $(\alpha=33 \pm 3$ ) were observed for samples sintered at $1050{ }^{\circ} \mathrm{C}$ for $2 \mathrm{~h}$. The better performance may be attributed to a greater number of varistor active grain boundaries per unit area. Because of the simplicity of the experiment, inexpensive sources of starting materials and better electrical characteristics, these materials have been successfully produced in a kilogram batch in an industrial pilot plant operation.

\section{Acknowledgements}

The authors gratefully acknowledge the financial support of Enterprise Ireland. We thank the Centre for Microscopy and Analysis Trinity College Dublin for their help with TEM and Dr M. Venkatesan, Department of Physics, Trinity College Dublin, for thermogravimetric analysis.

\section{References}

1 T. K. Gupta, J. Am. Ceram. Soc., 1990, 73, 1817(a) P. R. Bueno, J. A. Varela and E. Longo, J. Eur. Ceram. Soc., 2008, 28, 529; (b) R. Clarke, J. Am. Ceram. Soc., 1999, 82, 485; (c) L. M Levinson and H. R. Philip, Am. Ceram. Soc. Bull., 1986, 65, 639.

2 S. Y. Chung, I. D. Kim and S. J. L. Kang, Nat. Mater., 2004, 3, 774.

3 (a) P. Duran, F. Capel, J. Tartaj and C. Moure, Adv. Mater., 2002, 14, 137; (b) P. Duran, F. Capel, J. Tartaj and C. Moure, J. Am. Ceram. Soc., 2001, 84, 1661.

4 J.-A. Park, Physica B (Amsterdam), 2008, 403, 639.

5 S. C. Pillai, J. M. Kelly, D. E. McCormack, P. O'Brien and R. Raghavendra, J. Mater. Chem., 2003, 13, 2586. 
6 S. C. Pillai, J. M. Kelly, D. E. McCormack and R. Raghavendra, Adv. Appl. Ceram., 2006, 105, 158.

7 M. Matsuoka, Jpn. J. Appl. Phys., 1971, 10, 736.

8 R. N. Viswanath, S. Ramasamy, R. Ramamoorthy, P. Jayavel and T. Nagarajan, Nanostruct. Mater., 1995, 6, 993.

9 (a) T. Asokan and R. Freer, J. Mater. Sci., 1990, 25, 2447; (b) J. Fan and R. Freer, Br. Ceram. Trans., 1993, 96, 221.

10 S. M. Haile, D. W. Johnson, G. H. Wiseman Jr and H. K. Bowen, J. Am. Ceram. Soc., 1989, 72, 2004.

11 (a) K. X. Ya, H. Yin, T. M. De and T. M. Jing, Mater. Res. Bull., 1998, 33, 1703; (b) K. X. Ya, W. T. Diao, H. Yin, T. M. De and T. M. Jing, Mater. Res. Bull., 1998, 32, 1165.

12 G. Westin, A. Ekstrand, M. Nygren, R. Osterlund and P. Merkelbach, J. Mater. Chem., 1994, 4, 615(a) G. Westin and M. Nygren, J. Mater. Chem., 1993, 3, 367; (b) A. Ekstrand, M. Nagren and G. Westin, J. Sol-Gel Sci. Technol., 1997, 8, 697.

13 S. Hingorani, V. Pillai, P. Kumar, M. S. Multani and D. O. Shah, Mater. Res. Bull., 1993, 28, 1303.

14 S. Hishita, Y. Yao and S.-I. Shirasaki, J. Am. Ceram. Soc., 1989, 72, 338

15 V. C. Sousa, A. M. Segadaes, M. R. Morelli and R. H. G. A. Kiminami, Int. J. Inorg. Mater., 1999, 1, 235.

16 Y. Li Z. Zhang, Z. Tang, F. Yuan and J. Li, Adv. Mater. Opt. Electron., 1999, 9, 205.

17 G. Hohenberger and G. Tomandl, J. Mater. Res., 1992, 7, 546.

18 S. C. Pillai, J. M. Kelly, D. E. McCormack and R. Raghavendra, J. Mater. Chem., 2004, 14, 1572.
19 S. C. Pillai, J. M. Kelly, D. E. McCormack and R. Raghavendra, Mater. Sci. Technol., 2004, $20,964$.

20 A. R. West, Solid State Chemistry and Its Applications, John Wiley \& Sons, London, 1984, p. 174.

21 L. Spanhel and M. A. Anderson, J. Am. Chem. Soc., 1991, 113, 2826.

22 E. A. Meulenkamp, J. Phys. Chem. B, 1998, 102, 5566.

23 S. C. Pillai, S. W. Boland and S. M. Haile, J. Am. Ceram. Soc., 2004 , 87, 1388.

24 G. Duffy, S. C. Pillai and D. E. McCormack, J. Mater. Chem., 2007, 17, 181.

25 R. F. Silva and M. E. D. Zaniquelli, Thin Solid Films, 2004, 449, 86.

26 L. Guo, Y. Ji, H. Xu, Z. Wu and P. Simon, J. Mater. Chem., 2003, 13, 754 .

27 H. Ferkel and R. J. Hellmig, Nanostruct. Mater., 1999, 11, 617.

28 S. Hingorani, V. Pillai, P. Kumar, M. S. Multani and D. O. Shah, Mater. Res. Bull., 1993, 28, 1303.

29 S. Hingorani, D. O. Shah and M. S. Multani, J. Mater. Res., 1995, 10, 461

30 I. Wei and X.-H. Wang, Nature, 2000, 404, 168(a) T. Sakuma, Mater. Sci. Forum, 1996, 20, 109.

31 A. Banarjee, T. R. Rammohan and M. J. Patani, Mater. Res. Bull., 2001, 36, 1259.

32 H. I. Oh and J. H. Kim, J. Electroceram. 2006, 1083, 17.

33 R. Einzinger, Annu. Rev. Mater. Sci., 1987, 17, 299.

34 E. Olsson, L. K. L. Falk and G. L. Dunlop, J. Mater. Res., 1985, 20, 4091 . 